\title{
Intramedullary nail after Masquelet bone graft fracture: A case report
}

\author{
$M$ van Heukelum MBChB, DA(SA), \\ N Ferreira BSc, MBChB, HDip Orth(SA), FC Orth(SA), MMed Orth \\ L Marais MBChB, FCS(Orth)(SA), MMed(Ortho) \\ University of KwaZulu-Natal, Pietermaritzburg, South Africa \\ Corresponding author: \\ Dr Nando Ferreira \\ Tumour, Sepsis and Reconstruction Unit \\ Department of Orthopaedic Surgery \\ Grey's Hospital \\ Nelson R Mandela School of Medicine \\ University of KwaZulu-Natal \\ Pietermaritzburg, South Africa \\ Tel: +27338973000 \\ Email: Nando.Ferreira@kznhealth.gov.za
}

Department of Orthopaedic Surgery, Grey's Hospital, Nelson R Mandela School of Medicine,

\begin{abstract}
Large bone defects are challenging to reconstruct and often require specialised treatment strategies, multiple surgeries and long treatment periods. When these bone defects are the result of chronic infection the complexity of the reconstructive process increases exponentially. In the subtrochanteric area of the femur, bone defects secondary to infection are especially challenging as skeletal stabilisation is difficult and internal fixation is considered with caution due to the risk of recurrent infection. We report a case of a 24-year-old male who was successfully treated with an intramedullary nail after a fracture through a subtrochanteric Masquelet bone graft site.
\end{abstract}

Key words: intramedullary nail, bi-Masquelet, Ilizarov, bone defect, reconstruction

\section{Background}

Managing large bone defects can be extremely challenging for the orthopaedic surgeon involved. In addition, patients are exposed to significant impairment for extended periods of time, often being exposed to multiple surgeries and prolonged discomfort. ${ }^{1-5}$ The critical limit for non-vascularised bone grafting is $4-6 \mathrm{~cm}$, with larger defects requiring alternative reconstructive techniques..$^{1-3,6}$ Large bone defects can arise as a result of a number of causes; the majority is either post-traumatic or following infection or malignancy. ${ }^{3,7,8}$

Bone defects following infection are especially challenging as recurrent infection is always a concern and limits the treatments options. Treatment becomes even more challenging when the defect is located in the femoral subtrochanteric region. Guidelines to the ideal treatment strategy in these situations are limited in the literature and prescriptive management based on established protocols is lacking.
A flexible and individualised approach to the treatment is required. ${ }^{2}$

The Masquelet technique has been used successfully in the management of bone defects secondary to chronic osteomyelitis and involves the formation of an induced membrane with delayed cancellous bone grafting. ${ }^{4,9}$ This technique often relies on external fixation for stability. External fixation around the proximal femur is uncomfortable and poorly tolerated by most patients. Complications are common, with pin-site infection being almost universally experienced..$^{10,11}$ Conversion from external fixation to internal fixation has been suggested to limit patient discomfort and decrease the risk of external fixatorrelated complications. The timing of this conversion is, however, controversial and the recurrence of infection remains a concern. ${ }^{12,13}$

We report a case of successful intramedullary femur nailing following a fracture through a subtrochanteric Masquelet bone graft site. 


\section{Case report}

A 24-year-old man was referred to our limb reconstruction unit with chronic osteomyelitis of the left proximal femur. He had previously been treated at two separate institutions. His initial treatment involved a proximal femoral locked plate for a closed subtrochanteric femur fracture following a motor vehicle accident. He presented to the second hospital with a subtrochanteric non-union and a broken plate. Plate removal revealed a post-operative infection with necrotic bone. Specimens taken during debridement cultured Staphylococcus aureus sensitive to cloxacillin and clindamycin. At this time his erythrocyte sedimentation rate (ESR) was $48 \mathrm{~mm} / \mathrm{h}$ and C-reactive protein (CRP) was $40 \mathrm{mg} / \mathrm{L}$.

The patient was subsequently referred to our unit for further management of his chronic osteomyelitis. The patient was a non-smoker, HIV negative and had a serum albumin of $41 \mathrm{~g} / \mathrm{L}$, classifying him as an A-host according to the Cierny and Mader classification. ${ }^{14}$ The diffuse subtrochanteric osteomyelitis and associated mechanical instability resulted in the patient being classified as anatomic type IV Cierny and Mader chronic

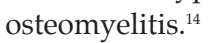

Surgical management was staged according to the prescribed Masquelet induced-membrane technique.,4,69 Debridement revealed a $12 \mathrm{~cm}$ necrotic subtrochanteric bone segment (Figure 1). All necrotic bone was debrided. An area of sub-periosteal new bone formation on the medial aspect of the proximal femur was well perfused and thus left intact. Soft tissues were closed over a gentamycin-impregnated form-fitting cement spacer (Figure 2). Stability was maintained using an Ilizarov circular external fixator (Smith and Nephew Inc., Memphis, TN, USA).

The second stage was performed eight weeks after the initial debridement. Infective markers were negative at this time and all clinical signs of infection had resolved. Surgery involved removal of the cement spacer followed by bone grafting into the induced membrane (Figure 3).

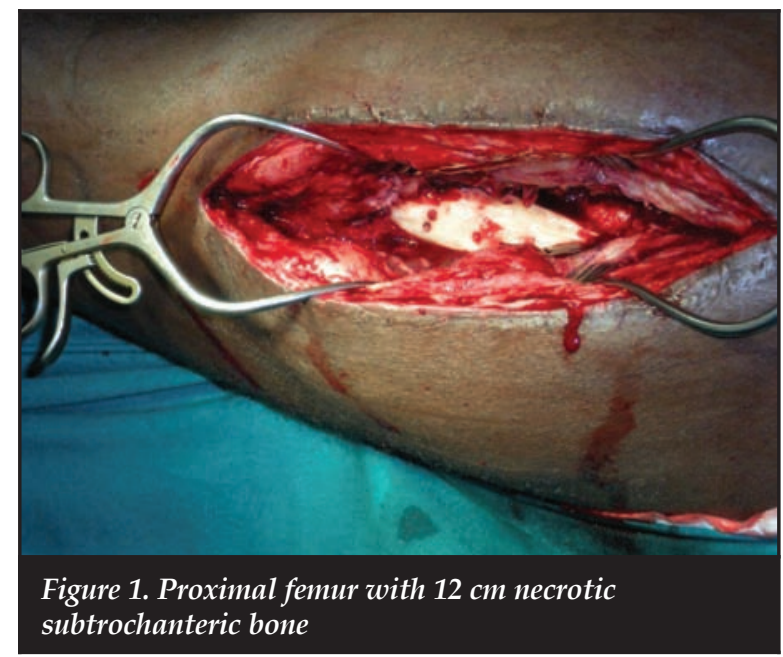

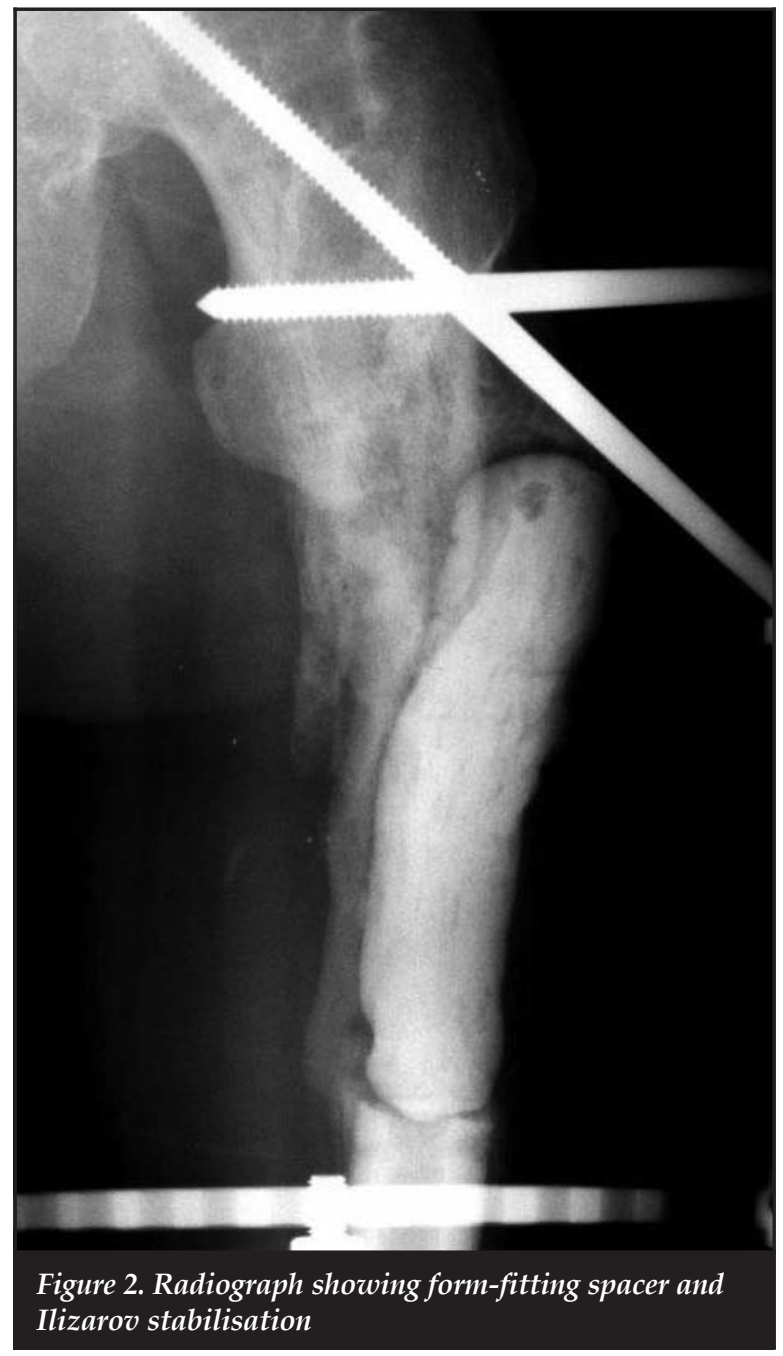

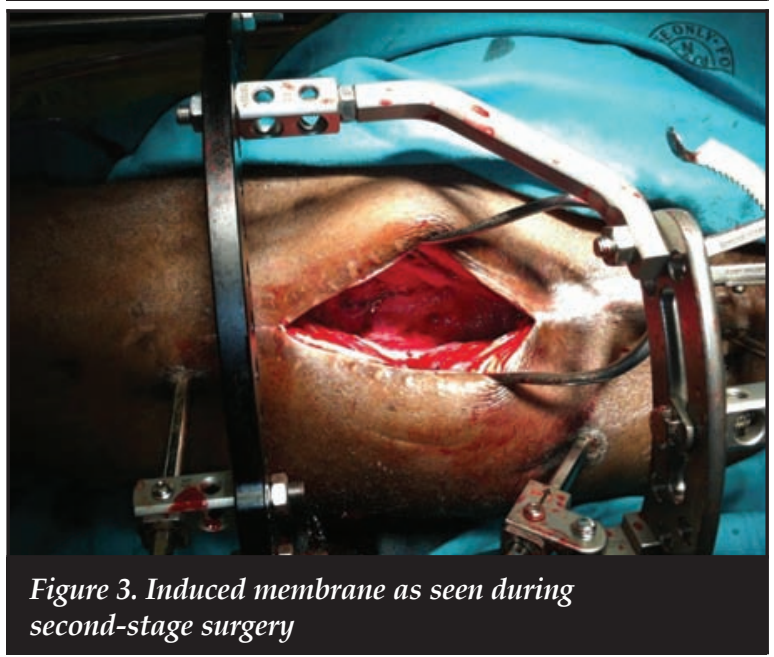

The reamer-irrigator-aspirator (RIA) (Synthes Inc, West Chester, PA) autograft, harvested without complication from the contralateral femur, was mixed with allograft bone chips and packed into the induced membrane surrounding the defect (Figure 4). 

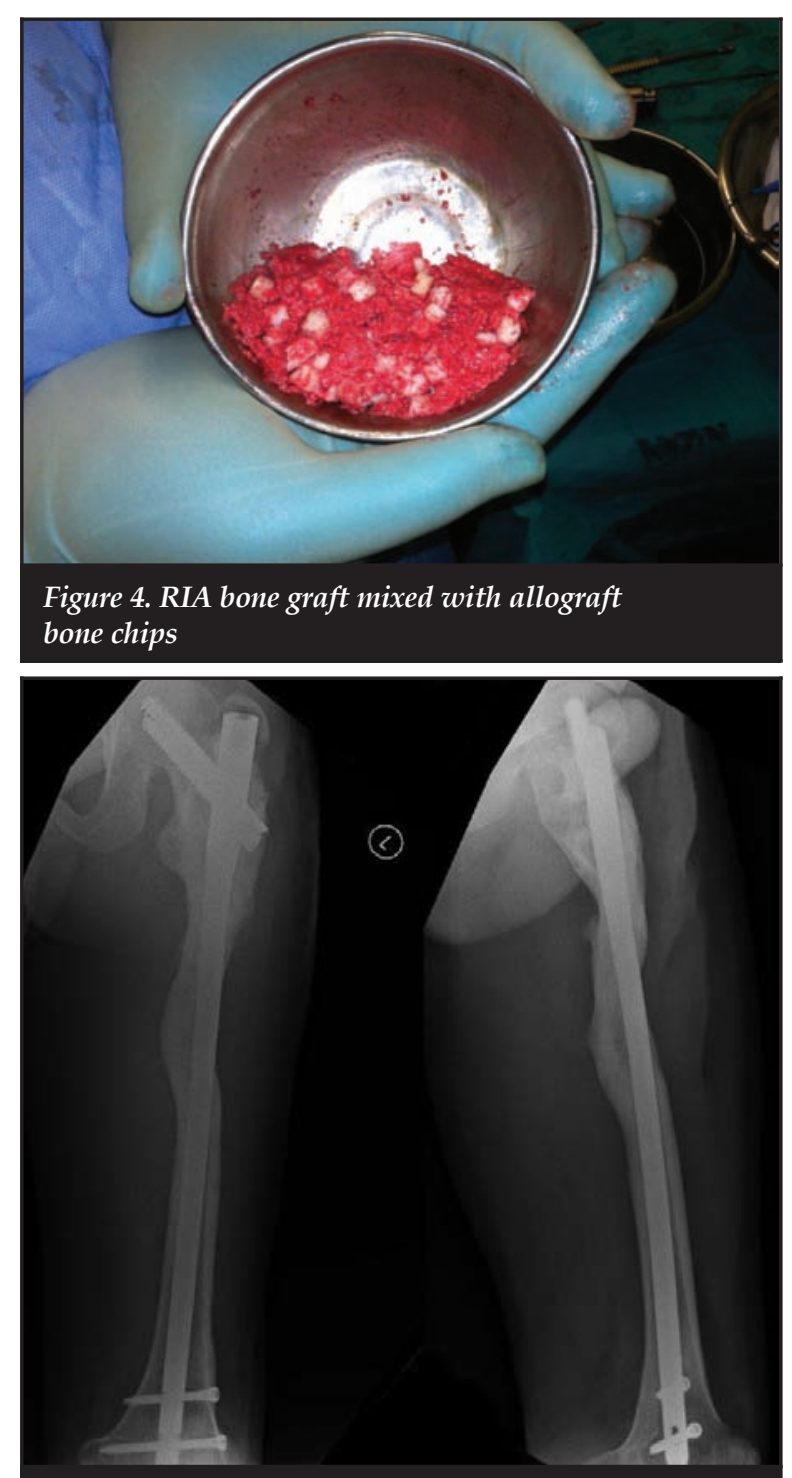

Figure 5. AP and lateral radiographs at last follow-up

The external fixator was removed once union was deemed adequate, five months after the bone graft procedure. A subsequent fall nine days after the frame was removed resulted in a fracture through the bone graft area. The soft tissues were not injured during the fall and inflammatory markers were normal. A Trigen InterTan (Smith and Nephew Inc., Memphis, TN, USA) cephalomedullary nail was chosen for stabilisation of the fracture. The nail was inserted without incident and the patient was mobilised immediately post-operatively.

At 20-months' follow-up the patient is able to ambulate without a walking aid and remains infection-free. Radiographic evaluation confirmed that the Masquelet bone graft fracture has healed and remodelled (Figure 5). We are not planning to remove the implant.

\section{Discussion}

Osteomyelitis causes bone necrosis, soft tissue compromise, functional impairment, systemic illness and considerable morbidity. ${ }^{5}$ Chronic osteomyelitis may begin as acute haematogenous or contiguous disease, the latter typically being introduced by open fracture or surgery. In 1983 Cierny and Mader classified chronic osteomyelitis based on four anatomical types and three physiological groups of patients (A, B \& C). ${ }^{14}$

Chronic osteomyelitis, as is the case with musculoskeletal tumours, can only be eradicated through complete resection of all necrotic tissue. Chemotherapy, in the form of antibiotics, only plays an adjuvant role. ${ }^{15}$

A curative approach resulted in a $12 \mathrm{~cm}$ subtrochanteric bone defect in our case. Bone defects greater than $4-6 \mathrm{~cm}$ are clinically challenging to treat and require specialised reconstructive techniques. ${ }^{1,2,16}$ Bone transport according to the Ilizarov method and bone graft into an induced membrane as described by Masquelet are two of the common techniques used. ${ }^{4,9,17,18}$ In very large defects, greater than $12 \mathrm{~cm}$, literature suggests that free vascularised fibular grafts provide the best results. ${ }^{19}$

The Masquelet technique is based on two principles or operative stages. ${ }^{4,9}$ The first stage relies on provoking a foreign body reaction around a cement spacer that is left in the osseous void for $4-8$ weeks. This results in the formation of an induced membrane into which cancellous bone graft is placed at a second stage. During this period an external fixator usually provides stability but internal fixation may also be used. The induced membrane acts as a resilient receptacle for the graft as well as preventing graft resorption..$^{4,20}$ The membrane also exhibits histological characteristics and biological properties that facilitate bone healing and revascularisation. ${ }^{6,21-23}$

The use of a solid form-fitting cement spacer provides additional advantages beyond the formation of the induced membrane. Local adjuvant antibiotics (usually vancomycin, gentamycin and or tobramycin) are aimed at eradicating persistent bacterial contamination. The solid spacer prevents involution of muscle, nerves and vascular structures into the defect, preventing them from becoming incorporated in the scar tissue that forms. ${ }^{24}$ Wound closure after bone grafting is also facilitated as soft tissues heal in an expanded position after the initial debridement thereby preventing contraction into the defect..$^{24}$

The Masquelet procedure results in the formation of large 'induced membranes' that require cancellous bone grafting. The RIA autograft system (Synthes Inc. West Chester, PA) allows intramedullary, non-structural autologous bone graft harvesting. ${ }^{25}$ Analyses of harvested graft demonstrate high concentrations of various growth factors including FGF-alpha, PDGF, IGF-I, BMP-2 as well as osteogenic differentiation of bone marrow progenitor cells. ${ }^{26-29}$ This suggests a tremendous therapeutic potential while maintaining the biological properties of the donor bone. ${ }^{25}$ 
Donor sites include the femur and tibia, and harvesting can be performed both antegrade or retrograde. In a recent study by Qvick et al., the mean volume of bone graft harvested was $25 \mathrm{ml}-69 \mathrm{ml}$, with a complication rate of $1.96 \% .^{30}$ In cases where a larger volume of graft is required, autologous graft can be combined with allograft to expand the volume while maintaining the benefits of autologous graft. ${ }^{31}$

As previously mentioned, one of the major challenges faced in managing bone defects is the provision of adequate bony stability. Adequate stability promotes revascularisation and maximises the host's immune response. Although there is currently a variety of fixation options available, external fixation is generally preferred. ${ }^{15}$ The advantage over open reduction and internal fixation or intramedullary nailing includes modularity of the construct, decreased deep infection risk and increased access for wound management after fixation is achieved. ${ }^{32}$ Literature suggests that the Ilizarov method of distraction osteogenesis significantly reduces the risk of deep infection in infected osseous lesions. ${ }^{33}$

The most common reasons for conversion to internal fixation include patient discomfort, persistent non-union and refracture. Conversion can be done acutely or delayed. Acute conversions involve the removal of the external fixator and insertion of internal fixation during the same surgery; this includes debridement of external fixation pin tracks and careful placement of the internal fixation device. Delayed conversion involves separate procedures for the removal of the external fixation and placement of the internal device, a so-called 'pinholiday'. Debridement of the pin tracks is done during the first procedure. Stability in the interval between the procedures relies on various methods including traction, plaster of Paris and functional braces. In our case, the patient had managed the external fixator well and did not experience any pin track complications. The conversion from external to internal fixation was delayed following a refracture secondary to a fall.

In this case report we present the findings and experiences of a single case, and we feel that this case confirms that the Masquelet technique can be used successfully to manage large subtrochanteric bone defects. It also confirms that one can successfully use intramedullary nailing through a Masquelet bone-graft site. We learnt that correct timing of the external fixator removal is essential as in our case union was not sufficient, which resulted in fracture through the bone graft site following minor trauma.

\section{Conclusion}

The Masquelet procedure is effective for the management of bone defects resulting from chronic osteomyelitis. It is labour-intensive and requires meticulous technique, lengthy hospitalisation and prolonged periods of external fixation. Internal fixation is a safe alternative to repeat external fixation in the setting of a fracture through a Masquelet bone-graft site.

\section{Consent}

Written consent was obtained from the patient for publication of this case report and any accompanying images. A copy of the written consent is available for review by the Editor-in-Chief of this journal.

The content of this article is the original work of the authors. No benefits of any form have been received or will be received from a commercial party related directly or indirectly to the subject of this article.

\section{References}

1. Lasanianos N, Kanakaris N, Giannoudis PV. Current management of long bone large segmental defects. Orthopaedics and Trauma. 2009;24:149-63.

2. Keating JF, Simpson AH, Robinson CM. The management of fractures with bone loss. J Bone Joint Surg [Br] 2005;87(2):142-50. PubMed PMID: 15736731.

3. Chaddha M, Gulati D, Singh AP, Singh AP, Maini L. Management of massive posttraumatic bone defects in the lower limb with the Ilizarov technique. Acta Orthop Belg 2010;76(6):811-20. PubMed PMID: 21302581.

4. Masquelet AC, Begue T. The concept of induced membrane for reconstruction of long bone defects. Orthop Clin North Am 2010;41(1):27-37. PubMed PMID: 19931050.

5. Donegan DJ, Scolaro J, Matuszewski PE, Mehta S. Staged bone grafting following placement of an antibiotic spacer block for the management of segmental long bone defects. Orthopedics 2011;34(11):e730-5. PubMed PMID: 22049954.

6. Motsitsi N. Masquelet's technique for management of long bone defects: from experiment to clinical application. East Cent Afr J Surg 2012;17(2):43-7.

7. El-Alfy B, El-Mowafi H, El-Moghazy N. Distraction osteogenesis in management of composite bone and soft tissue defects. Int Orthop 2010;34(1):115-8. PubMed PMID: 18493758. Pubmed Central PMCID: 2899258.

8. Manish K, Rabi J. Bone transport in tibial gap non-union: A series of 25 cases. Open J Orthop 2012;2:144-9.

9. Masquelet AC, Fitoussi F, Begue T, Muller GP. [Reconstruction of the long bones by the induced membrane and spongy autograft]. Ann Chir Plast Esthet. 2000;45(3):346-53. PubMed PMID: 10929461. Reconstruction des os longs par membrane induite et autogreffe spongieuse.

10. Bibbo C, Brueggeman J. Prevention and management of complications arising from external fixation pin sites. $J$ Foot Ankle Surg 2010;49(1):87-92. PubMed PMID: 20123298. 
11. Rogers LC, Bevilacqua NJ, Frykberg RG, Armstrong DG. Predictors of postoperative complications of Ilizarov external ring fixators in the foot and ankle. J Foot Ankle Surg 2007;46(5):372-375. PubMed PMID: 17761322.

12. Monni T, Birkholtz FF, De Lange $\mathrm{P}$, Snyckers $\mathrm{CH}$. Conversion of external fixation to internal fixation in a non-acute, reconstructive setting: a case series. Strat Traum Limb Reco. 2013;8:25-30.

13. Yokoyama K, Uchino M, Nakamura K, Ohtsuka H, Suzuki $\mathrm{T}$, Boku $\mathrm{T}$, et al. Risk factors for deep infection in secondary intramedullary nailing after external fixation for open tibial fractures. Injury 2006;37(6):554-60. PubMed PMID: 16352306.

14. Cierny G, 3rd, Mader JT, Penninck JJ. A clinical staging system for adult osteomyelitis. Clin Orthop Relat Res 2003;414:7-24. PubMed PMID: 12966271.

15. Marais LC, Ferreira N, Aldous C, Le Roux TLB. The managemet of chronic osteomyelitis. Part I Diagnostic work-up and surgical principles. SA Orthop $J$ 2014;13(2):42-48.

16. Kesemenli C, Subasi M, Kirkgoz T, Kapukaya A, Arslan $\mathrm{H}$. Treatment of traumatic bone defects by bone transport. Acta Orthop Belg 2001;67(4):380-86. PubMed PMID: 11725571.

17. Ilizarov GA. The tension-stress effect on the genesis and growth of tissues: Part II. The influence of the rate and frequency of distraction. Clin Orthop Relat Res 1989;239:263-85. PubMed PMID: 2912628.

18. Ilizarov GA. The tension-stress effect on the genesis and growth of tissues. Part I. The influence of stability of fixation and soft-tissue preservation. Clin Orthop Relat Res 1989;238:249-81. PubMed PMID: 2910611.

19. El-Gammal TA, Shiha AE, El-Deen MA, El-Sayed A, Kotb $\mathrm{MM}$, Addosooki AI, et al. Management of traumatic tibial defects using free vascularized fibula or Ilizarov bone transport: a comparative study. Microsurgery. 2008;28(5):339-46. PubMed PMID: 18537173.

20. Karger C, Kishi T, Schneider L, Fitoussi F, Masquelet AC, et al. Treatment of posttraumatic bone defects by the induced membrane technique. Orthop Traumatol Surg Res 2012;98(1):97-102. PubMed PMID: 22244249.

21. Ferreira N, Marais LC. Open tibial bone transport following a failed bi-Masquelet procedure - a case report. SA Orthop J 2012;12(4):50-53.

22. Uzel AP, Lemonne F, Casoli V. Tibial segmental bone defect reconstruction by Ilizarov type bone transport in an induced membrane. Orthop Traumatol Surg Res 2010;96(2):194-98. PubMed PMID: 20417920.

23. Viateau V, Bensidhoum M, Guillemin G, Petite H, Hannouche D, Anagnostou F, et al. Use of the induced membrane technique for bone tissue engineering purposes: animal studies. Orthop Clin North Am 2010;41:49-56.
24. Richard MJ, Creevy WR, Tornetta P, 3rd. The use of solid form-fitting antibiotic cement spacers in bone loss of the lower extremity. Curr Orthop Prac 2012;23(5):453-58.

25. Stafford PR, Norris BL. Reamer-irrigator-aspirator bone graft and bi Masquelet technique for segmental bone defect nonunions: a review of 25 cases. Injury 2010;41 Suppl 2:S72-7. PubMed PMID: 21144933.

26. McCall TA, Brokaw DS, Jelen BA, Scheid DK, Scharfenberger AV, Maar DC, et al. Treatment of large segmental bone defects with reamer-irrigator-aspirator bone graft: technique and case series. Orthop Clin North Am 2010;41(1):63-73; table of contents. PubMed PMID: 19931054.

27. Porter RM, Liu F, Pilapil C, Betz OB, Vrahas MS, Harris $\mathrm{MB}$, et al. Osteogenic potential of reamer irrigator aspirator (RIA) aspirate collected from patients undergoing hip arthroplasty. J Orthop Res 2009;27(1):42-49. PubMed PMID: 18655129. Pubmed Central PMCID: 2648608.

28. Schmidmaier G, Herrmann S, Green J, Weber T, Scharfenberger A, Haas NP, et al. Quantitative assessment of growth factors in reaming aspirate, iliac crest, and platelet preparation. Bone 2006;39(5):1156-63. PubMed PMID: 16863704.

29. Wenisch S, Trinkaus K, Hild A, Hose D, Herde K, Heiss C, et al. Human reaming debris: a source of multipotent stem cells. Bone 2005;36(1):74-83. PubMed PMID: 15664005.

30. Qvick LM, Ritter CA, Mutty CE, Rohrbacher BJ, Buyea $\mathrm{CM}$, Anders MJ. Donor site morbidity with reamerirrigator-aspirator (RIA) use for autogenous bone graft harvesting in a single centre 204 case series. Injury 2013;44(10):1263-69. PubMed PMID: 23845569.

31. Finkemeier CG. Bone-grafting and bone-graft substitutes. J Bone Joint Surg [Am] 2002;84-A(3):454-64. PubMed PMID: 11886919.

32. Moss DP, Tejwani NC. Biomechanics of external fixation: a review of the literature. Bull Hosp Jt Dis 2007;65(4):29499. PubMed PMID: 18081548.

33. Papakostidis C, Bhandari M, Giannoudis PV. Distraction osteogenesis in the treatment of long bone defects of the lower limbs: effectiveness, complications and clinical results; a systematic review and meta-analysis. Bone Joint J 2013;95-B(12):1673-80. PubMed PMID: 24293599.

This article is also available online on the SAOA website (www.saoa.org.za) and the SciELO website (www.scielo.org.za). Follow the directions on the Contents page of this journal to access it. 